Published in final edited form as:

J Consult Clin Psychol. 2013 April ; 81(2): 284-298. doi:10.1037/a0030814.

\title{
Gender-Specific Effects of an Augmented Written Emotional Disclosure Intervention on Posttraumatic, Depressive, and HIV- Disease-Related Outcomes: A Randomized, Controlled Trial
}

\author{
Gail Ironson, \\ University of Miami \\ Conall O'Cleirigh, \\ Harvard Medical School, Massachusetts General Hospital \\ Jane Leserman, \\ University of North Carolina, Chapel Hill \\ Rick Stuetzle, \\ University of Miami \\ Joanne Fordiani, \\ VA Boston Healthcare System, Boston, Massachusetts, and Boston VA Research Institute, \\ Boston, Massachusetts \\ MaryAnn Fletcher, and \\ University of Miami \\ Neil Schneiderman \\ University of Miami

\section{Abstract} \\ Objective-Trauma histories and symptoms of PTSD occur at very high rates in people with \\ HIV and are associated with poor disease management and accelerated disease progression. The \\ authors of this study examined the efficacy of a brief written trauma disclosure intervention on \\ posttraumatic stress, depression, HIV-related physical symptoms, and biological markers of HIV \\ disease progression.
}

Method-HIV-infected men and women were randomized to four 30-min expressive writing sessions in either a treatment (trauma writing) or an attention control (daily events writing) condition. The disclosure intervention augmented the traditional emotional disclosure paradigm

(C) 2012 American Psychological Association

Correspondence concerning this article should be addressed to Gail Ironson, Department of Psychology, University of Miami, 412 Flipse Building, 5665 Ponce de Leon Boulevard, Coral Gables, FL 33146. gironson@ aol.com.

Gail Ironson, Department of Psychology, University of Miami; Conall O'Cleirigh, Department of Psychiatry, Harvard Medical School, Massachusetts General Hospital; Jane Leserman, Department of Psychiatry, University of North Carolina, Chapel Hill; Rick Stuetzle, Department of Psychology, University of Miami; Joanne Fordiani, VA Boston Healthcare System, Boston, Massachusetts, and Boston VA Research Institute, Boston, Massachusetts; MaryAnn Fletcher and Neil Schneiderman, Department of Psychology,

University of Miami. 
with probes to increase processing by focusing on trauma appraisals, self-worth, and problem solving. Outcomes were assessed at baseline, 1-, 6-, and 12-month follow-up.

Results-Hierarchical linear modeling ( $N=244$, intent-to-treat analyses) revealed no significant treatment effects for the group as a whole. Gender by treatment group interactions were significant such that women in the trauma-writing group had significantly reduced posttraumatic stress disorder (PTSD) symptoms $(p=.017)$, depression $(p=.009)$, and HIV-related symptoms $(p=$. 022) compared with their controls. In contrast, men in the trauma-treatment condition did not improve more than controls on any outcome variables. Unexpectedly, men in the daily-eventwriting control group had significantly greater reductions in depression then men in the traumawriting group. Treatment effects were magnified in women when the analysis was restricted to those with elevated PTSD symptoms at baseline.

Conclusions-A brief (4-session) guided written emotional disclosure intervention resulted in significant and meaningful reductions in PTSD, depression, and physical symptoms for women with HIV, but not for men.

\section{Keywords}

expressive writing; emotional disclosure; HIV; trauma; PTSD

The prevalence of traumatic and stressful life events among people with HIV is alarmingly high, and there is a large body of research documenting the deleterious effects of trauma on health behaviors, health status, and disease progression. People living with HIV report high rates of sexual and physical abuse ( $>50 \%$, Whetten et al., 2006), other life stresses and traumas (>90\%, Pence et al., 2007; 61\%; Gore-Felton, Butler, \& Koopman, 2001), and posttraumatic stress disorder (PTSD; 61\%; Gore-Felton et al., 2001; Kimerling, Calhoun, et al., 1999; Leserman et al., 2005; Whetten et al., 2006; Whetten, Reif, Whetten, \& MurphyMcMillan, 2008). Rates of trauma are high for both sexes. They are, however, particularly elevated in HIV-infected women: $55 \%$ of women versus $38 \%$ of men met criteria for acute stress disorder (Israelski et al., 2007), and 68\% of women versus 35\% of men report having experienced sexual assault (Kalichman, Sikkema, DiFonzo, Luke, \& Austin, 2002).

Previous research has documented the detrimental impact of trauma, stress, depression, and PTSD on immune changes, physical functioning, and disease progression in HIV infection (Burack et al., 1993; Chida \& Vedhara, 2009; Leserman, 2008; Leserman et al., 2002, 2005, 2007; Ickovics et al., 2001; Ironson et al., 2005; Kemeny \& Dean, 1995; Kemeny, Weiner, Duran, \& Taylor, 1995; Kimerling, Armistead, \& Forehand, 1999; Mayne, Vittinghoff, Chesney, Barrett, \& Coates, 1996; O’Cleirigh, Skeer, Mayer, \& Safren, 2009). In addition, stress and trauma have been associated with adverse health behaviors that hinder the management of HIV such as low adherence (Leserman, Ironson, O'Cleirigh, Fordiani, \& Balbin, 2008) and high risk behaviors (Reisner, Mimiaga, Safren, \& Mayer, 2009). Studies have also shown that coping with stress and trauma by means of avoidance and denial may lead to immune decrements and faster HIV disease progression (Chida \& Vedhara, 2009; Ironson et al., 1994, 2005; Leserman et al., 2002; Moskowitz, Hult, Bussolari, \& Acree, 2009; Temoshok, Wald, Synowski, \& Garzino-Demo, 2008). Thus, a substantial number of 
studies support the notion that trauma and denial or repression of emotion may have deleterious effects on the health status of patients with HIV.

The health and psychological benefits of brief expressive writing (EW) interventions have been the focus of many studies, with generally positive results (see comprehensive review of 146 studies in Frattaroli, 2006). More specifically, emotional disclosure studies have shown that writing about trauma, compared with writing about trivial events, has salutary health effects in reducing physical symptom reports and health center visits, depression, and pain, and in improving physical functioning (Frisina, Borod, \& Lepore, 2004; Gidron et al., 2002; Pennebaker \& Beall, 1986; Pennebaker \& Susman, 1988; Richards, Beal, Seagal, \& Pennebaker, 2000; Smyth, 1998; Smyth, Stone, Hurewitz, \& Kaell, 1999). Meta-analyses of trauma writing have shown variable effects on psychological status ranging from no effect (Frisina et al., 2004; nine studies) to moderate effects (Frattaroli, 2006; 146 studies) to large effects ( $d=0.66$; Smyth, 1998; 13 studies).

However, most of the studies comprising these meta-analyses were conducted in healthy student samples; few focused on the medically ill. Interestingly, a meta-analysis of nine emotional-disclosure interventions limited to nonstudent clinical samples (e.g., asthma, arthritis, cancer) showed that expressive writing was more effective in improving physical health than psychological well-being (Frisina et al., 2004). On the other hand, Harris (2006) reported that writing about stressful experiences was associated with fewer health care visits only in the healthy samples (13 studies), not in medically ill samples (9 studies) or psychologically stressed samples (10 studies). In the few studies of the individuals with medical illnesses in which physical symptoms were included as an outcome variable (Willmott, Harris, Gellaitry, Cooper, \& Horne, 2011, who studied 179 myocardial infarction patients; Smyth, Stone, et al., 1999, who studied 112 patients with asthma and rheumatoid arthritis; Broderick, Junghaenel, \& Schwartz, 2005, who studied 92 fibromyalgia patients; Stanton et al., 2002, who studied 60 women with breast cancer; and Rosenberg et al., 2002, who studied 30 men with prostate cancer), a therapeutic effect was found with effect sizes (d) ranging from 0.42 to 0.62 (Broderick et al., 2005; Frisina et al., 2004; Willmott et al., 2011). Modest effects of EW have been found on pain in patients with rheumatoid arthritis (Lumley et al., 2011) and with cancer, but only in those with high emotional disclosure (Cepeda et al., 2008). Some studies have found no effect of EW on physical symptoms; of note, Harris, Thoresen, Humphreys, and Faul (2005) failed to replicate the Smyth et al. (1999) findings in 137 asthma patients; Low, Stanton, Bower, and Gyllenhammer (2010) failed to find an effect in 62 metastatic breast cancer patients; and van Middendorp, Geenen, Sorbi, van Dooren, and Bijlsma (2009) failed to find an effect in 68 rheumatoid arthritis patients. Gillis, Lumley, Mosley-Williams, Leisen, and Roehrs (2006) found delayed (to 3month follow-up) benefits of limited clinical significance in 83 fibromyalgia patients. In one study of 50 adolescents with asthma, Warner et al. (2006) found an effect on physical symptoms only when the analysis was restricted to those above the median. Nonetheless, the preponderance of findings suggests that EW is associated with fewer reported physical symptoms, warranting a trial in patients with HIV.

The effect of emotional disclosure through writing in HIV-infected samples has been evaluated in only a few studies of randomized controlled trials (RCTs). Petrie, Fontanilla, 
Thomas, Booth, and Pennebaker (2004) found a significant protective effect of trauma writing on CD4 + lymphocyte counts but not viral load (VL) with a sample of 37 people with HIV. Rivkin, Gustafson, Weingarten, and Chin (2006) studied a writing intervention focused on living with HIV (rather than trauma) and reported no effect on depression or on beta 2 microglobulin in 79 people with HIV but did not measure CD4 counts, VL, or trauma symptoms. Wagner, Hilker, Hepworth, and Wallston (2010) found no effects of trauma writing (vs. trivial writing control) on psychological outcomes, pain, or physical functioning in 37 people with HIV. Wyatt et al. (2004) used trauma writing as part of her integrated risk reduction/prevention intervention in people with HIV and found a positive impact on sexual risk reduction and adherence to medications in those who attended more sessions. Of interest, none of these studies included PTSD symptoms or physical symptoms as outcomes.

Only a few studies have examined the effect of EW on PTSD symptoms; some selected for PTSD and others did not. In the largest RCT of EW in people with PTSD (150 women who had been raped), Resick et al. (2008) found a significant improvement in PTSD symptoms and depression. Three smaller studies of people with PTSD—Sloan, Marx, and Greenberg's (2011) study of 42 undergraduates; Smyth, Hockemeyer, and Tulloch's (2008) study of 25 people from a Veterans Administration or rape crisis center; and Bugg, Turpin, Mason, and Scholes' (2009) of 67 traumatic injury patients (with elevated acute stress disorder)— showed no effect of EW on PTSD symptoms between intervention and control groups, although the Smyth et al. (2008) study did find improvement in mood and posttraumatic cognitions. Studies in which there was no selection for PTSD diagnosis but in which PTSD symptoms were measured as an outcome variable have also had mixed results, with Sloan and Marx (2004) finding a significant decrease in PTSD symptoms, depression, and physical symptoms in 49 undergraduate students, and Schoutrop, Lange, Hanewald, Davidovich, and Salomon (2002) finding a significant effect on intrusion, avoidance, and depressive symptoms, whereas Gidron, Peri, Connolly, and Shalev (1996) found no beneficial effect in 14 trauma victims. Thus, the literature is mixed with respect to effects of EW on PTSD symptoms.

A few other (nonintervention) studies in HIV bear on the issues of emotional expression and emotional-cognitive processing and health in HIV. In a study of 80 HIV-positive gay men, Cole, Kemeny, Taylor, and Visscher (1996) found that those who concealed their homosexuality had faster disease progression. After controlling for health behaviors, demographics, and treatment regimen, Eisenberger, Kemeny, and Wyatt (2003) found that higher inhibition words were associated with lower CD4 counts. These studies support a theoretical rationale that inhibition may be a pathway to poorer health. In addition, our own preliminary work in this area has linked processing of reappraisals, self-esteem, and coping efficacy within the context of written emotional disclosure of stressful experiences to symptom-free and long-term survival in patients with HIV/AIDS (O'Cleirigh et al., 2003; O'Cleirigh, Ironson, Fletcher, \& Schneiderman, 2008). This work has also has shown that emotional processing is a better predictor of disease progression over 1 year, improved immune status (CD4 and natural killer [NK] cells), and better health behaviors than emotional disclosure alone (O'Cleirigh et al., 2002). As this work suggested that emotionalcognitive processing of trauma (in addition to emotional disclosure) was protective of health in individuals with HIV, the disclosure intervention was augmented to stimulate emotional- 
cognitive processing in particular areas. Specifically, as part of each of the written disclosure tasks, patients wrote about their understanding or appraisal of the traumatic situation, feelings of self-worth and self-esteem, and coping or problem-solving efforts in response to the trauma. We view this augmented trauma-writing intervention as theoretically consistent with other empirically supported treatments for PTSD such as cognitive processing therapy (Resick \& Schnicke, 1992; 1996) and prolonged exposure (Foa \& Kozak, 1986), whose key elements are cognitive restructuring and exposure. This augmented brief written disclosure intervention also is theoretically consistent with conceptualizations of the necessary conditions for therapeutic resolution of stressful experiences (i.e., overcoming recurring patterns of avoidance and rumination through exposure to distressing memories and subsequent emotional processing; Foa \& Kozak, 1986; Horowitz, 1986).

In summary, there is enough evidence suggesting that an emotional disclosure intervention might have a beneficial effect on both psychological and physical health in patients with HIV to warrant an RCT. We hypothesized that those writing about trauma would have reduced PTSD symptoms, depression, HIV-related symptoms, and HIV VL and increased CD4 lymphocytes.

\section{Method}

\section{Study Sample}

Our study sample was recruited from HIV-infected men and women in south Florida (Miami-Dade and Broward County) from February 2004 through January 2009 (with follow-up assessments through February 2010). Research participants were recruited from community organizations (e.g., positive connections), doctors' offices, family health clinics in minority neighborhoods, relevant events (AIDS walk, gay pride), gay gathering places (bars, bookstores, and so forth), newspaper and newsletter advertisements, and word of mouth. As indicated in the consort statement flow chart (Figure 1), we screened 1,128 HIV infected men and women for inclusion/exclusion criteria, 264 were enrolled and underwent baseline assessment, and 244 were randomized (121 to the intervention and 123 to the control group). Randomization was stratified on gender, education (high school education or less vs. more education), and use of highly active antiretroviral therapy (HAART) to ensure that the treatment and control groups were equivalent on these variables. Of those randomized, $10.7 \%$ (13/121 in treatment, 13/123 in control) were lost to contact (or withdrew, $n=4$ included in that figure) between baseline and 1-month follow-up (F1), another $6.1 \%$ were lost to contact (or withdrew, $n=3$ ) between F1 and 6-month follow-up (F6; 5/105 treatment and 8/109 control), and 6.8\% were lost between F6 and 12-month follow-up (F12). The overall dropout rate (lost to contact or withdrew) to 12 months was thus $22.3 \%$ (27/121) in the treatment group and 20.3\% (25/123) in the control group. (We did not include those who were deceased or incarcerated or had moved in this calculation). Although these rates may be considered high, note that this is a low socioeconomic status (SES) group often without the resources to have a stable home or cell phone. Dropout rates did not differ between groups. 


\section{Inclusion and Exclusion Criteria}

We recruited HIV-positive people in the mid-range of illness. We wanted to eliminate patients who had little room for improvement (CD4 >600) or whose disease progression $(\mathrm{CD} 4<100)$ would likely overshadow a trauma reduction treatment (when retested by our labs, $85 \%$ fell into a CD4 range of 100-600). We included those with one Category C symptom (AIDS defining) historically but excluded those with $\mathrm{C}$ symptoms in the year prior to entering the study. Although subjects were part of a stress or trauma treatment study (writing about stress or trauma), we assumed the stress of HIV was sufficient to enter the study and did not require the presence of additional trauma. Other exclusion criteria included those younger than 18 and older than 70 years; those who were illiterate or could not write at an eighth-grade level, confirmed by the Test of Written Language (3rd ed.; Hammill \& Larsen, 1996); those with active systemic diseases or disorders that would interfere with participation or confound prediction of disease progression (e.g., heart, lung, kidney, liver, cancer, or stroke); those with current alcohol or substance dependence or psychotic symptoms (confirmed by the appropriate Structured Clinical Interview for DSM$I V$ module (First, Spitzer, Gibbon, \& Williams, 1997); those who were planning to change HIV medications within 6 months or who had changed HIV medications in the previous 3 months; those initiating use of antidepressant medication during the month before the study; those had undergone surgery with general anesthesia in the previous 3 months; and those who could not commit to four treatment sessions.

\section{Procedures}

The institutional review board at the University of Miami approved the study, and all patients signed an informed consent at the beginning of their initial screening visit (baseline). Blood was drawn, and questionnaires and interviews were administered at the baseline visit. Participants returned for the first study visit $(N=244)$ where they were randomized to either the augmented trauma-writing intervention or the daily-event-writing control. Both experimental and control participants were asked to visit the study on four occasions during a 2- to 4-week period so that they could write for $30 \mathrm{~min}$ in a private office. After each writing session, the writings were submitted to the researchers. Questionnaires, interviews, and blood draws again were administered at 1, 6, and 12 months after the end of the writing intervention.

Experimental condition (augmented trauma-writing) instructions-During the 4 writing days, participants were asked to write about the most traumatic or upsetting experiences of their entire life. In their writing, they were asked to "really let go" and explore their "very deepest emotions and thoughts." Subjects were told that it was best to write about a major trauma and encouraged to write about the same experience on all 4 days. However, they were told it was okay if they wrote about current conflicts. Subjects were encouraged to write about traumas or conflicts they had not discussed in great detail with others. They were told to write continuously for $20 \mathrm{~min}$. These instructions were based upon those used in previous studies (Kelley, Lumley, \& Leisen, 1997; Pennebaker, Barger, \& Tiebout, 1989; Pennebaker \& Beall, 1986). When the 20-min writing session was completed, subjects were asked to write for an additional $10 \mathrm{~min}$ and given the following instructions (processing probes) for each session, respectively-Session 1: How you have 
tried to understand and make sense of the traumatic experience(s)?; Session 2: How does the traumatic experience affect your feelings about yourself, your self-worth, and your selfesteem?; Session 3: How does the traumatic experience affect your ability to solve problems, to meet future challenges, or to deal with day-to-day stress?; and Session 4: How have you tried to understand the trauma and make sense of it?

Control condition (daily-event-writing) instructions-Those in the control condition were asked to write a description about what they did "yesterday from the time [they] got up until the time [they] went to bed" for 20 min continuously. They were told to "avoid writing about [their] emotions or opinions" but to try to be as "accurate and objective as possible."

The 20-min writing period was followed by 10 more min of describing in writing what they had done "today from the time [they] woke in the morning." These instructions were modified slightly for three subsequent writing sessions to reflect descriptions of what they did on different days or what they planned to do on future days.

\section{Measurement}

\section{HIV disease progression and health measures}

CD4 counts: Flow cytometry was performed in one lab to enumerate CD3 + CD4 lymphocytes with fluorochrome conjugated monoclonal antibodies in a four-color system.

Viral load (VL): HIV-1 VL was performed with the Roche Amplicor RT/PCR assay (Roche Molecular Diagnostics, Pleasanton, CA), which measures down to 400 copies of HIV RNA in plasma.

HIV symptom checklist: Experimenters assessed symptoms relevant to HIV (based on the Centers for Disease Control and Prevention criteria for Category B symptoms) by interview using an HIV symptom checklist. Symptoms were assessed for the previous month at baseline and the 1 month visit, and for the previous 6 months, at the 6-month and 12-month visits; thus, symptoms were assessed during the whole follow-up period. Examples of symptoms are herpes zoster (shingles), oral thrush, cervical dysplasia, pelvic inflammatory disease, low platelet count $(<50,000)$, peripheral neuropathy, chronic unexplained fever, and chronic unexplained diarrhea.

\section{Psychosocial/distress assessment measures}

Davidson PTSD Scale (PTSDTOT; Davidson et al., 1997; Zlotnick, Davidson, Shea, \&

Pearlstein, 1996): This scale is a 17 -item interview-administered measure based on the PTSD symptom clusters defined by Diagnostic and Statistical Manual of Mental Disorders (4th ed.; American Psychiatric Association, 1994). Each item is rated from 0 to 4 for both frequency and severity during the past week. Items are summed for a total score, and subscales measure re-experiencing, avoidance, and arousal. The total scale has demonstrated good test-retest reliability $(r=.86)$ and internal consistency $(r=.99)$. In diagnosing PTSD compared with the SCID, the positive predictive value was $92 \%$ and the negative predictive value was 79\%, with a cutoff score of 40 for PTSD suggested by Davidson (1996). 
Hamilton Depression Scale (HAM-D): This 17-item interview-based measure is considered the gold standard for assessing severity of depression (Hamilton, 1967). Our team has found high interrater reliability with intraclass correlation coefficient of .95. Our assessments for the Hamilton and Davidson PTSD scales were done by interviewers who were blind to group assessment, except in a few rare cases.

Manipulation check: Adherence to probes: Essays were scored from the first writing session to determine whether people were paying attention to the directions (e.g., to ensure that the daily-writing group was not writing about trauma and that the trauma-condition group wrote about trauma and attended to the probe question). In all cases, directions were followed.

\section{Statistical Analysis}

Hierarchical linear models (HLM) were used to evaluate study outcomes. Because HLM uses all randomized participants, these are intent-to-treat analyses. We conducted analyses on HLM Version 6.06 software (Raudenbush, Bryk, Cheong, Congdon, \& du Toit, 2004). Level-1 and Level-2 data sets were prepared with SPSS Version 17.0. The Level-1 model includes only the time variable, which provides the structure of the analysis and captures within-person change over time. The time structure, months since baseline, was held constant within-subject and was based upon the mean number of months since baseline for each assessment time point. In the Level-2 model, between-person characteristics, such as treatment condition, gender, and their interaction, are used to predict the slope estimates representing change in the dependent variables. For the Level-2 models, the baseline value of the dependent variable was included as a covariate to ensure that individual variation at study entry was controlled in the calculation of the slope estimates. HIV symptoms were dichotomous, and they were modeled using a Bernoulli distribution with a correction for overdispersion. For all HLM models, continuous measures in the Level-2 model were centered around their group means, and all dichotomous variables were coded 1/0 to allow for more meaningful evaluation of parameter estimates. For model parameters, we used restricted maximum-likelihood estimation with robust standard errors. We tested unconstrained models to confirm significant individual variation about the slope and intercept before accounting for random assignment. Treatment effects were evaluated by an examination of the significance of the gamma coefficient associated with treatment condition in the Level-2 model. Gamma $(\gamma)$ represents the change in the slope over time of the dependent variable of interest (for example, PTSD symptoms) predicted from the independent variable of interest (in this case, group assignment), with any other variables in the Level-2 model (in this case, baseline PTSD symptoms) controlled. Follow-up analyses of the gender-moderated effects were examined with models that included group treatment condition, gender, baseline value of the outcome, and the group by gender interaction in the Level-2 model. For analyses involving VL, we used the log transformation; however, means are presented using actual values. Comparisons between treatment conditions on demographic and disease-related variables were done with $t$ tests (for continuous variables) and chi-square tests (for categorical variables). We calculated effect sizes (Cohen's $d$ ) for pre-post using the mean difference divided by the standard deviation $(S D)$ of the differences. Effect size for between-group change (pre-post trauma writing vs. pre-post 
control writing) is the mean pre-to-post difference in the trauma-writing group minus the mean pre-to-post difference in the daily-events-writing group divided by the weighted average of the $S D$ of the difference scores within the trauma-writing group and $S D$ of the difference scores within the daily-events-writing group.

\section{Results}

There were 244 research participants randomly assigned to the treatment $(N=121)$ or control $(N=123)$ groups. The average age of the sample was 42.8 years old $(S D=8.8)$. The sample was ethnically and racially diverse with more than half the sample (56\%) identifying as African American or Afro Caribbean. Whites and Hispanics were similarly represented with each group accounting for slightly less than $20 \%$ of the sample (17\% and $19.5 \%$, respectively). Women composed about $40 \%(39.3 \%=96 / 244)$ of the sample, and $42.6 \%$ of the entire sample identified as gay or bisexual. About $30 \%$ of the sample had not graduated from high school, although nearly half of the sample had educational experiences beyond high school (43\% had some college or trade school, and 5.4\% were college graduates). The only demographic variable that differed significantly between experimental and control groups was the age difference, $t(242)=2.12, p=.035$, with the controls being slightly younger (2.4 years). None of the other demographic variables differed significantly between the groups with all $p \mathrm{~s}>.2$. The mean CD4 cell number at study entry was $439(S D=235)$, and the mean number of HIV RNA viral copies in plasma was about 32,890 $(S D=98,869)$, which places the average study participant in the mid-range of HIV disease. Two thirds of the sample reported currently taking highly active antiretroviral medications. There were no significant differences between the groups on any of the disease characteristics.

\section{Treatment Effects}

The significance of the treatment effects were evaluated by examining the significance of the difference between the slopes (rate of change) of the study outcomes for the traumawriting and daily-writing-conditions from baseline through 1, 6, and 12 months postintervention (means and $S D$ s are in Table 1 and the significance tests are in the first part of Table 2). None of the psychological or HIV disease progression markers differed between treatment conditions.

\section{Gender-Moderated Effects}

In the absence of significant main treatment effects, gender was examined as a moderator by testing gender by group interaction effects on the study outcomes using HLM as described in the Method section (second part of Table 2). In contrast to the main effects analyses, significant interaction effects for gender by condition were observed over time for PTSD symptoms, HAM-D, and HIV-related physical symptoms. Specifically, women receiving the trauma-writing treatment showed significantly greater reductions at follow-up in the severity of their PTSD symptoms, depression, and HIV-related physical symptoms than women in the control condition (tests in Table 3, Column A; descriptives in Table 4, Column A). Analyses of women alone (Table 3, Column A) show that the PTSD effect was driven by reductions in both avoidance and intrusions compared with controls' levels of avoidance and intrusion. In men alone (Table 3, Column B \& Table 4, Column B), with the 
exception of HAM-D, there was no significant effect of group (group by time interaction) on any of the outcome measures. For depression, although both groups' scores decreased over time, this reduction was only significant in the daily-writing group: daily $\gamma=-1.36$, $t(72)=-3.91, p=.003$; trauma $\gamma=-.22, t(68)=-0.55, p=.581$. For PTSD in the men, both trauma- and daily-event-writing groups experienced significant decreases over time; trauma $\gamma=-3.27, t(69)=-2.17, p=.033$; control $\gamma=-4.91, t(73)=-3.11, p=.003$.

An examination of the gender-moderated effect on HIV-related physical symptoms was also significant (second part of Table 2). An examination of the means shows that women in the trauma-writing condition were significantly less likely to report HIV-related symptoms at follow-up than women in the control condition (Table 3, Column A \& Table 4, Column A). For the men (Table 3, Column B \& Table 4, Column B), there were no significant differences between treatment conditions in the likelihood of reporting HIV-related symptoms. There were no significant gender by group effects for CD4 or VL (Table 2).

Table 4 presents the means and SDs at baseline, 1-, 6-, and 12-month follow-up separately for women and men for each of the study outcomes that showed a significant group by gender interaction. An examination of the trends in the mean differences across treatment conditions reported for women and men elucidate the moderated effects and analyses reported in Tables 2 and 3. For women, but not men, the trauma writing was significantly associated with reductions in PTSD, depression, and HIV-related symptoms over time compared with controls.

Because the effects of trauma writing appeared to reduce PTSD symptoms in women, a post hoc examination of the subset of women for whom this reduction would be most clinically relevant (e.g., women with elevated PTSD symptoms [above the median of 20] at entry to the study) was conducted. This analysis would be justified only if PTSD symptoms at baseline moderated the relationship between group assignment and improvement (i.e., people with elevated PTSD improved more with the intervention). The group by baseline PTSD score interaction was significant in women, $\gamma=.074, t(91)=2.32, p=.023$, so we proceeded to analyze the subset of women with elevated PTSD symptoms (PTSDTOT $>=$ $20)$. We chose the median rather than the PTSD cutoff to present in order to maximize the sample size and to include the subclinical as well as clinical range. ${ }^{1}$ Table 3 , Column C, shows the results of the significance tests, and Table 5 shows the means and $S D$ s across time for this subset of women on the clinically relevant variables. There was a significant effect of the intervention (group by time interaction) for PTSD symptoms (including significant reductions in avoidance, numbing, and hyper-arousal), depression, and HIV-related physical symptoms. Figure 2 shows the change in mean PTSD symptoms over time in each treatment condition for women with elevated PTSD at baseline $(>=20)$. The figure illustrates that there is a significantly greater reduction in PTSD symptoms in the trauma- versus the dailywriting control group and that this reduction is maintained over time.

\footnotetext{
${ }^{1}$ A comparable test for women with PTSD scores at or above the diagnostic cutoff of 40 at baseline was performed and was significant as well. The group by time effect for PTSD symptoms: $\square=5.05, t(24)=2.80, p=.01$ Within the trauma group, the prepost effect sizes are 1.24 and 1.24 at 6 and 12 months, respectively. The between-group effect sizes are .67 and .58 , respectively.
} 
The comparable tests for men with initial PTSD scores greater than $20(n=85)$ showed no significant effect of group (trauma-writing vs. daily-writing control) by time interactions for PTSD symptoms, $\gamma=-1.74, t(82)=-1.51, p=.13)$, HAM-D $(\gamma=-.55, t(80)=-1.60, p=$. 11 , or HIV symptoms, $\gamma=.13, t(82)=1.07, p=.29$.

Effect sizes (Table 6) on PTSD symptoms for this most clinically relevant group (women with elevated PTSD symptoms at baseline) are large for pre-to-post changes in PTSD in the trauma-writing group (Cohen's $d s=1.12$ and 1.15 at 6 and 12 months, respectively). The parallel effect sizes for the group assignment interaction were more moderate (pre-post differences on PTSD in the trauma-writing vs. the control group: Cohen's $d \mathrm{~s}=0.63$ and 0.45 at 6 and 12 months, respectively). All other effect sizes for outcomes of PTSD and depression are in Table 6 and are given for women only, men only, and the combined group.

\section{Discussion}

Within a large and diverse sample of HIV-positive men and women, no significant treatment effects were observed for any of the hypothesized study outcomes (depressive or PTSD symptoms, HIV-related symptoms, CD4 count, or HIV RNA viral load) for the group as a whole. However, there were significant gender by treatment group interaction effects. Among women only, the written trauma disclosure condition was associated with significant reductions in PTSD symptoms, symptoms of depression, and physical symptoms compared with a daily-events-writing control condition. Effects were even stronger for women with elevated PTSD symptoms at baseline. For men, an unexpected finding was that they had a greater decrease in depression in the daily-events-writing control condition than in the trauma-writing condition.

Our nonsignificant effects of trauma disclosure on PTSD symptoms are consistent with the findings of a number of studies of EW (Bugg et al., 2009; Sloan et al., 2011; Smyth et al., 2008) while seeming to be inconsistent with others (Resick et al., 2008; Schoutrop et al., 2002; Sloan \& Marx, 2004), at least until gender is taken into account (see later discussion). Why would there be no significant effects of trauma writing on symptoms of PTSD and depression? From a cognitive-behavioral perspective, the primary theories of trauma resolution involve habituation through exposure (Foa \& Kozak, 1986) or emotionalcognitive processing, including restructuring of thoughts (Resick \& Schnicke, 1992, 1996). The current intervention utilized the EW task, which is self-paced, and even with additional probes to increase emotional-cognitive processing, the task may not be as potent as having a therapist who can identify "stuck points" and work with the client to restructure thoughts, or who knows when to push for further exposure and when a person's defenses may be overwhelmed. In addition, habituation is not likely to occur unless the fear structure is accessed and repeatedly exposed until anxiety subsides. These processes can be avoided in this self-controlled task. There is also no assigned homework, which in cognitive processing therapy involves identifying, challenging, and restructuring beliefs, or in exposure treatment involves a real-life in-vivo hierarchy of exposures. Given these considerations, as Lumley, Tojek, and Macklem (2002) noted, perhaps researchers should be looking for characteristics of people that identify who may benefit from expressive writing. 
This study suggests that gender may be one of these characteristics. Why would there be gender differences? The benefits of EW are thought to depend on the ability of people to access, express, process, and ultimately resolve negative emotional memories (Lumley et al., 2002; Pennebaker, 1997). As hypothesized by Lumley et al. (2002), alexithymic people (who have deficits in emotional awareness and understanding) may derive less benefit from EW because they are less able to access and express emotions. To the extent that men may be more alexithymic than women, women may derive more benefit from EW. Other research has found that women are more emotionally expressive than men (Brody, 1997). Another moderator relevant to gender differences is the finding by Kraft, Lumley, D'Souza, and Dooley (2008) that patients with greater emotional approach coping (which may be more characteristic of women) derived more benefits from EW. In fact, Stanton, Kirk, Cameron, and Danoff-Burg (2000) showed that when students were dealing with a parent's illness, matching the intervention with the student's emotional approach tendency (for expressing emotions or receiving facts) was associated with better coping. It is possible that the men in our study may have used less emotional approach coping or may not have benefitted to the same extent as women from processing trauma. In addition, perhaps the additional instructions to augment emotional-cognitive processing in the trauma-writing condition may have interfered with men's processing while enhancing women's processing. In addition to differences in emotional awareness, expression, processing, and emotional approach coping, which may have affected PTSD recovery, several hypotheses may be raised regarding the lack of recovery of men from depression in the trauma-writing group compared with those in the daily-writing group: Perhaps the trauma writing was more upsetting for the men, making them more depressed, or perhaps the observation that the trauma was not resolved as well in men assigned to trauma writing may have been reflected in the lack of recovery from depression. Other possible reasons for the gender difference, which we intend to explore in future analyses, are that the women might be more engaged or involved in the writing task or that women write about different or more severe traumas. The latter is not likely since PTSD scores at baseline did not differ between men and women. It is also notable that the loss to follow-up for women was about half of the loss for men (see $n$ s in Table 4). Finally, effects of life context and stigma may have played a role. Our women were predominantly African American (78\%) and may have faced greater stigma from HIV in their community and have had less opportunity to safely disclose their status than the men, who were predominantly gay or bisexual (65\%). Gay men can more easily seek out communities supportive of people with HIV.

How do our findings on gender differences compare with other emotional disclosure literature? In the largest meta-analysis to date, Frattaroli (2006) reviewed 146 emotional disclosure randomized studies and found no gender differences on mental or physical health outcomes. However, a large proportion of these studies $(96 / 146=63.7 \%)$ were conducted on college student samples, often recruited from psychology classes. However, Frattaroli (2006) reported that studies with a higher proportion of men had a larger effect size ( $r=$. 18). In his meta-analysis of 13 studies, Smyth (1999) also found that studies with a higher proportion of men had higher overall effect sizes, but the proportion of men was unrelated to psychological well-being or physiological functioning (p. 179) and gender effects were not directly tested. There are also theoretical reasons why men might be expected to gain more 
from EW than women - because men are often socialized to inhibit emotional expression that makes them look weak or less masculine (Brody, 1996). Finally, it should be noted that the current study comprises a patient sample very different on key characteristics from the more typical samples reported in the emotional disclosure research: The two most predominant groups in our sample were African American women and gay men, and our sample was predominantly lower SES (mean annual income was $\$ 10,000$ ) people. In addition, as noted, our writing task was augmented with specific directions designed to increase emotional-cognitive processing. It is plausible that men may not benefit from processing to the same extent as women, and therefore, the addition of probes in the current study may well have fostered gender differences.

\section{Gender-Moderated Effects in Emotional Disclosure}

Specifically, among all women in the trauma-writing group, PTSD symptoms decreased by $38 \%$ and $35 \%$ at 6- and 12-month follow-ups, respectively. The effect sizes on PTSD symptoms among all women in the trauma treatment were modest $(d s=0.21$ and 0.22 at 6 and 12 months, respectively) compared with those in the control condition. However, when examining the women more at risk (those with PTSD at baseline >20), the reduction in PTSD symptoms was 50\% at 6 months and $46 \%$ at 12 months, and the effect size on PTSD symptoms for trauma-writing women compared with the daily-writing controls was moderate ( $d \mathrm{~s}=0.63$ and 0.45 , respectively) at 6 and 12 months. These interaction effect sizes are in the range of effect sizes reported for empirically supported treatments for PTSD, such as cognitive-behavioral therapy, prolonged exposure, and stress management among populations meeting PTSD criteria. Compared with the effect sizes in credible control groups (not waitlist or usual care), trauma-focused cognitive-behavioral therapy effects have been modest to large ( $d \mathrm{~s}=0.27$ to 1.01) in meta-analyses (Bisson \& Andrew, 2005; Bradley, Greene, Russ, Durta, \& Westen, 2005). The 46\%-50\% reduction in PTSD symptoms found for women with elevated PTSD symptoms is comparable to what has been found in some of the RCTs in which cognitive processing therapy has been used (12 sessions with rape victims, Resick, Nishith, Weaver, Astin, \& Feuer, 2002; and 10 sessions with combat veterans, Monson et al., 2006), slightly less than what was found in Resick et al. (2008; five sessions with sexual abuse victims), and not as great as in others (Chard, 2005; 18 sessions with childhood sexual abuse victims).

As noted in the introduction, in addition to our study, only a few writing studies have included PTSD symptoms as an outcome. In view of our findings, it is instructive to review these studies with respect to gender and effect sizes. In a non-HIV sample of 150 adult women with PTSD, Resick et al.'s (2008) effect size (pre-post change) for writing about trauma was similar to what we found in women with PTSD (Davidson PTSDTOT >40) at baseline ( $d=1.24$ for our study at 6 and 12 months using pre-post change) ${ }^{2}$ Interestingly, Resick et al. (2008) found that writing about trauma was about as effective as the full cognitive processing therapy protocol (cognitive therapy including writing) at 6-month follow-up in reducing symptoms of depression and PTSD, although it was not as effective as

\footnotetext{
${ }^{2}$ The estimation of pre-post effect size (ES) on PTSD symptoms from the Resick et al. (2008) study requires the estimation of a correlation between pre and post scores. Using $r=.60$ (the correlation in our data), her ES $=1.43$; using a more conservative $r=.50$, her $\mathrm{ES}=1.30$. Note also that her study had five sessions of writing, whereas ours had four.
} 
the full protocol immediately posttreatment. A study of trauma writing by Sloan and Marx (2004) of 49 undergraduate women who experienced one or more traumatic stressors found a significant decrease in PTSD symptoms ( $\mathrm{ES}=.43$ ), depression $(\mathrm{ES}=.72)$, and physical symptoms (Pennebaker Inventory of Limbic Languidness; Pennebaker, 1982; ES = .49). Similarly, Schoutrop et al. (2002) found a significant effect of trauma writing on intrusions, avoidance, and depressive symptoms among 48 undergraduates ( $75 \%$ women) randomly assigned to write about a traumatic experience that still bothered them or to a wait list control. In contrast, the studies with mixed genders found weaker or no effects: Sloan et al. (2011) focused on 42 undergraduates with PTSD and found no effect on PTSD symptoms or depression. Gidron et al. (1996) studied 14 victims of motor vehicle accidents and found no beneficial effect of trauma writing. Similarly, Bugg et al. (2009) studied 67 trauma injury patients with acute stress disorder and found no effect of writing on anxiety, PTSD, or depression. Finally, one study of volunteers with PTSD $(N=25)$ from a Veterans Administration or rape and trauma center (11 males, 14 females) did not show an effect of EW on PTSD symptoms but did find improvements in mood and posttraumatic growth (Smyth et al., 2008). A later study of Gidron et al. (2007) also showed gender differences in a trauma recall intervention (not a writing study) of traffic accident victims-where a significant group by gender interaction revealed a reduction of PTSD symptoms for women but not for men. This literature, together with our results, suggests that writing about trauma may be particularly beneficial for reducing PTSD symptoms in women.

Another important clinical observation from the literature and from our study is that reductions in PTSD symptoms when writing about trauma (or, more broadly, exposure therapy or cognitive-behavioral therapy for trauma) appear to be accompanied by reduction in depressive symptoms as well. The reductions in symptoms of depression (HAM-D) in our study of $31 \%$ and $26 \%$ for all women at 6 - and 12-month follow-ups, respectively, and of 56\% and $40 \%$ for women with elevated PTSD at baseline are both statistically significant and clinically substantial. The effect sizes associated with these reductions in depressive symptoms (women with elevated PTSD symptoms: $d s=0.89$ pretreatment/0.68 posttreatment; and women with PTSD: $d \mathrm{~s}=0.91$ intervention/ 0.47 controls) also are comparable to the findings for trauma-focused cognitive-behavioral therapy when compared with credible control groups (not waitlist or usual care), which have been modest to large ( $d s$ ranging from 0.28 to 1.08; Bisson \& Andrew, 2005; Bradley et al., 2005). This suggests that treating PTSD may have the added benefit of reducing depression and raises the underlying question of whether the source of the depression may have been the trauma.

The impact of trauma writing on HIV-related physical symptom reports in women was also significant and substantial. In women writing about trauma, physical symptom reports decreased by $52 \%$ (means decreasing from 0.27 to 0.13 ), whereas in the control group, symptom reports increased by $20 \%$ (means increasing from .31 to .39) by the 6-month follow-up. At 12 months, the reduction in symptom reports was $22 \%$ (means decreasing from .27 to .21 ) in the trauma group compared with a $20 \%$ increase in the control group (means increasing from .31 to .39). These reductions in physical symptoms associated with trauma writing are similar to the reductions in psychological symptoms and add to the small 
but growing literature (noted in the introduction) suggesting that EW may have an impact on physical symptoms in the medically ill.

Finally, it is important to note that there were no effects on our objective measures of CD4 and VL. While all effects that were found are subjective, note that assessment of outcomes through interview with an assessor blind to treatment should have minimized the subjectivity and that the control group had the same subjective measure bias.

Our findings also extend the literature on EW in HIV, since no other prior studies in HIV have included physical symptom reports or PTSD symptoms. It does contrast with the Petrie et al. (2004) study, which found an impact on CD4 cells; we did not find such an impact in ours but that study was smaller $(n=37)$ and the participants were mostly men $(35 / 37)$. Our negative finding for the sample as a whole in alleviating depression is consistent with Rivkin et al. (2006). However, we did find effects for women, whereas they did not explore gender differences. Furthermore, their sample had few women (21 out of 79). Note also that their participants wrote about living with HIV, rather than trauma per se, and did not have the augmented processing probes.

\section{Future Research}

Research is needed in a larger sample of HIV-positive women with PTSD to determine whether the effects of writing will replicate. Determining who might benefit from this intervention, as was examined by Stanton et al. (2000, 2002) and Lumley et al. (2002), would be useful. It would also be useful to know how this brief, transportable intervention would compare with therapy. Research is also needed to determine if the findings regarding significant reduction in PTSD symptoms in women can be extended to other clinical populations with PTSD (not just HIV) and can extend to other HIV-relevant health-related outcomes such as sexual risk behavior or medication adherence. In addition, our unexpected findings in men of a significantly greater benefit of the daily-events-writing control group on depression need to be replicated. If the findings are replicated, this raises the question of whether a focus on daily activities may be more beneficial than a focus on processing the trauma for recovery from depression, at least in the context of a self-paced written task. Although writing about one's worst trauma (emotional disclosure) has been tested among students and persons with chronic medical illness, it has not been placebo-controlled tested in a reasonably powered sample with sexual abuse histories or PTSD. Finally, we had a large number of exclusion criteria, and it would be useful to determine whether this brief writing intervention could be helpful to a wider clinical population.

\section{Limitations of the Study}

Although our study had a large sample size and used clinician-independent assessment for PTSD and depression, with established diagnostic cutoffs and not just self-reported currentaffect measures, there are several limitations. We did not test whether the processing probes added anything to the traditional written disclosure paradigm since we did not have a trauma-writing group that did not receive the probes. We screened out a large proportion of people who could potentially benefit from the intervention, (e.g., those with current substance dependence). 


\section{Clinical Implications}

This is the first study to show that the writing paradigm (by itself) has useful clinical effects (reduction in PTSD symptoms, depression, and HIV symptoms) in women with HIV.

However it is important to note that we screened out anyone for whom a brief intervention might not be appropriate (mental instability, substance dependence, and so on). With our screening procedure in place, we found surprisingly few people (about 10\%; 23 out of 244) who needed extra contact during the course of the study. We identified these people immediately after the writing sessions by elevated Subjective Units of Distress (SUDS; >80) or elevated Profile of Mood States (McNair, Lorr, \& Droppleman, 1992) anger scores. These people were distributed evenly between the trauma-writing $(n=14)$ and daily-events-writing $(n=9)$ conditions, and thus, in most cases, the need for extra contact (mood checks with 510 min of clinician-guided discussion) was not specifically related to the trauma writing. Thus, likely because EW is self-directed and self-paced, our data show it appears to be safe and involves no increased risk. Finally, there was no compelling data to suggest that men derived any clinical benefit from augmented trauma writing. In combination with previous literature, this finding suggests it is advisable to use the standard trauma-writing paradigm for men rather than trauma writing with the augmented probes used in this study.

\section{Conclusion}

A brief emotional disclosure treatment (writing about trauma augmented by probes to encourage processing) appears to significantly benefit women, but not men, in terms of reducing symptoms of PTSD, depression, and physical symptoms of HIV. Its potential for use as an adjunct treatment in women should be considered and investigated further.

\section{Acknowledgments}

This study was supported by National Institutes of Health/National Center for Complementary and Alternative Medicine Grant R01 AT002035 (Gail Ironson, Principal Investigator). The authors would like to thank Rachel Ruffin, James Blount, and Heidemarie Kremer for assisting in conducting the study; Abby Sheer and Jonathan Atwood for data management; and Blanche Freund and Elizabeth Balbin.

\section{References}

American Psychiatric Association. Diagnostic and statistical manual of mental disorders. 4. Washington, DC: Author; 1994.

Bisson J, Andrew M. Psychological treatment of post-traumatic stress disorder (PTSD). Cochrane Database of Systematic Reviews. 2005; 2:CD003388. [PubMed: 15846661]

Bradley R, Greene J, Russ E, Dutra L, Westen D. A multidimensional meta-analysis of psychotherapy for PTSD. The American Journal of Psychiatry. 2005; 162:214-227.10.1176/appi.ajp.162.2.214 [PubMed: 15677582]

Broderick JE, Junghaenel DU, Schwartz JE. Written emotional expression produces health benefits in Fibromyalgia patients. Psychosomatic Medicine. 2005; 67:326-334.10.1097/01.psy. 0000156933.04566.bd [PubMed: 15784801]

Brody LR. Gender and emotion: Beyond stereotypes. Journal of Social Issues. 1997; 53:369_ 393.10.1111/j.1540-4560.1997.tb02448.x

Bugg A, Turpin G, Mason S, Scholes C. A randomised controlled trial of the effectiveness of writing as a self-help intervention for traumatic injury patients at risk of developing post-traumatic stress disorder. Behaviour Research and Therapy. 2009; 47:6-12.10.1016/j.brat.2008.10.006 [PubMed: 19012880] 
Burack JH, Barrett DC, Stall RD, Chesney MA, Ekstrand ML, Coates TJ. Depressive symptoms and CD4 lymphocyte decline among HIV-infected men. Journal of the American Medical Association. 1993; 270:2568-2573.10.1001/jama.1993.03510210054027 [PubMed: 7901433]

Cepeda MS, Chapman C, Miranda N, Sanchez R, Rodriguez CH, Restrepo AE, Carr DB. Emotional disclosure through patient narrative may improve pain and well-being: Results of a randomized controlled trial in patients with cancer pain. Journal of Pain and Symptom Management. 2008; 35:623-631.10.1016/j.jpainsymman.2007.08.011 [PubMed: 18359604]

Chard KM. An evaluation of cognitive processing therapy for the treatment of posttraumatic stress disorder related to childhood sexual abuse. Journal of Consulting and Clinical Psychology. 2005; 73:965-971.10.1037/0022-006X.73.5.965 [PubMed: 16287396]

Chida Y, Vedhara K. Adverse psychosocial factors predict poorer prognosis in HIV disease: A metaanalytic review of prospective investigations. Brain, Behavior, and Immunity. 2009; 23:434445.10.1016/j.bbi.2009.01.013

Cole SW, Kemeny ME, Taylor SE, Visscher BR. Accelerated course of human immunodeficiency virus infection in gay men who conceal their homosexual identity. Psychosomatic Medicine. 1996; 58:219-231. [PubMed: 8771621]

Davidson, J. Davidson Trauma Scale. North Tonawanda, NY: Multi-Health Systems; 1996.

Davidson JRT, Book SW, Colket JT, Tupler LA, Roth S, David D, Feldman ME. Assessment of a new self-rating scale for post-traumatic stress disorder. Psychological Medicine. 1997; 27:153160.10.1017/S0033291796004229 [PubMed: 9122295]

Eisenberger NI, Kemeny ME, Wyatt GE. Psychological inhibition and CD4 T-cell levels in HIVseropositive women [Special issue]. Journal of Psychosomatic Research. 2003; 54:213224.10.1016/S0022-3999(02)00473-7 [PubMed: 12614831]

First, MB.; Spitzer, RL.; Gibbon, M.; Williams, JBW. User's guide for the Structured Clinical Interview for DSM-IV Axis I Disorders-Clinician Version (SCID-CV). Washington, DC: American Psychiatric Press; 1997.

Foa EB, Kozak MJ. Emotional processing of fear: Exposure to corrective information. Psychological Bulletin. 1986; 99:20-35.10.1037/0033-2909.99.1.20 [PubMed: 2871574]

Frattaroli J. Experimental disclosure and its moderators: A meta-analysis. Psychological Bulletin. 2006; 132:823-865.10.1037/0033-2909.132.6.823 [PubMed: 17073523]

Frisina PG, Borod JC, Lepore SJ. A meta-analysis of the effects of written emotional disclosure on the health outcomes of clinical populations. Journal of Nervous and Mental Disease. 2004; 192:629634.10.1097/01.nmd.0000138317.30764.63 [PubMed: 15348980]

Gidron Y, Duncan E, Lazar A, Biderman A, Tandeter H, Shvartzman P. Effects of guided written disclosure of stressful experiences on clinic visits and symptoms in frequent clinic attenders. Family Practice. 2002; 19:161-166.10.1093/fampra/19.2.161 [PubMed: 11906981]

Gidron Y, Gal R, Givati G, Lauden A, Snir Y, Benjamin J. Interactive effects of memory structuring and gender in preventing posttraumatic stress symptoms. Journal of Nervous and Mental Disease. 2007; 195:179-182.10.1097/01.nmd.0000254676.11987.5d [PubMed: 17299308]

Gidron Y, Peri T, Connolly JF, Shalev AY. Written disclosure in posttraumatic stress disorder: Is it beneficial for the patient? Journal of Nervous and Mental Disease. 1996; 184:505506.10.1097/00005053-199608000-00009 [PubMed: 8752081]

Gillis ME, Lumley MA, Mosley-Williams A, Leisen JC, Roehrs T. The health effects of at-home written emotional disclosure in fibromyalgia: A randomized trial. Annals of Behavioral Medicine. 2006; 32:135-146.10.1207/s15324796abm3202_11 [PubMed: 16972811]

Gore-Felton C, Butler LD, Koopman C. HIV disease, violence, and posttraumatic stress. Focus. 2001; 16:5-6. [PubMed: 11547387]

Hamilton M. Development of a rating scale for primary depressive illness. British Journal of Social and Clinical Psychology. 1967; 6:278-296.10.1111/j.2044-8260.1967.tb00530.x [PubMed: 6080235]

Hammill, DD.; Larsen, SC. TOWL-3: Test of Written Language. 3. Circle Pines, MN: American Guidance Service; 1996. 
Harris AHS. Does expressive writing reduce health care utilization? A meta-analysis of randomized trials. Journal of Consulting and Clinical Psychology. 2006; 74:243-252.10.1037/0022-006X. 74.2.243 [PubMed: 16649869]

Harris AHS, Thoresen CE, Humphreys K, Faul J. Does writing affect asthma? A randomized trial. Psychosomatic Medicine. 2005; 67:130-136.10.1097/01.psy.0000146345.73510.d5 [PubMed: 15673635]

Horowitz MJ. Stress-response syndromes: A review of posttrauatic and adjustment disorders. Hospital and Community Psychiatry. 1986; 37:241-249. [PubMed: 3957267]

Ickovics JR, Hamburger ME, Vlahov D, Schoenbaum EE, Schuman P, Boland RJ, Moore J. Mortality, CD4 cell count decline, and depressive symptoms among HIV-seropositive women: Longitudinal analysis from the HIV epidemiology research study. Journal of the American Medical Association. 2001; 285:1466-1474.10.1001/jama.285.11.1466 [PubMed: 11255423]

Ironson G, Friedman A, Klimas N, Antoni M, Fletcher MA, LaPerriere A, Schneiderman N. Distress, denial, and low adherence to behavioral interventions predict faster disease progression in gay men infected with HIV. International Journal of Behavioral Medicine. 1994; 1:90-105.10.1207/ s15327558ijbm0101_6 [PubMed: 16250807]

Ironson G, O’Cleirigh C, Fletcher MA, Laurenceau JP, Balbin E, Klimas N, Solomon G. Psychosocial factors predict CD4 and viral load change in men and women with human immunodeficiency virus in the era of highly active antiretroviral treatment. Psychosomatic Medicine. 2005; 67:10131021.10.1097/01.psy.0000188569.58998.c8 [PubMed: 16314608]

Israelski DM, Prentiss DE, Lubega S, Balmas G, Garcia P, Muhammad M, Koopman C. Psychiatric comorbidity in vulnerable populations receiving primary care for HIV/AIDS. AIDS Care. 2007; 19:220-225.10.1080/09540120600774230 [PubMed: 17364402]

Kalichman SC, Sikkema KJ, DiFonzo K, Luke W, Austin J. Emotional adjustment in survivors of sexual assault living with HIV-AIDS. Journal of Traumatic Stress. 2002; 15:289-296.10.1023/A: 1016247727498 [PubMed: 12224800]

Kelley JE, Lumley MA, Leisen JCC. Health effects of emotional disclosure in rheumatoid arthritis patients. Health Psychology. 1997; 16:331-340.10.1037/0278-6133.16.4.331 [PubMed: 9237085]

Kemeny ME, Dean L. Effects of AIDS-related bereavement on HIV progression among New York City gay men. AIDS Education and Prevention. 1995; 7(Suppl):36-47. Retrieved from http:// guilfordjournals.com/loi/aeap. [PubMed: 8664097]

Kemeny ME, Weiner H, Duran R, Taylor SE. Immune system changes after the death of a partner in HIV-positive gay men. Psychosomatic Medicine. 1995; 57:547-554. [PubMed: 8600481]

Kimerling R, Armistead L, Forehand R. Victimization experiences and HIV infection in women: Associations with serostatus, psychological symptoms, and health status. Journal of Traumatic Stress. 1999; 12:41-58.10.1023/A:1024790131267 [PubMed: 10027141]

Kimerling R, Calhoun KS, Forehand R, Armistead L, Morse E, Morse P, Clark L. Traumatic stress in HIV-infected women. AIDS Education and Prevention. 1999; 11:321-330. [PubMed: 10494356]

Kraft CA, Lumley MA, D’Souza PJ, Dooley JA. Emotional approach coping and self-efficacy moderate the effects of written emotional disclosure and relaxation training for people with migraine headaches. British Journal of Health Psychology. 2008; 13:6771.10.1348/135910707X251144 [PubMed: 18230235]

Leserman J. Role of depression, stress, and trauma in HIV disease progression [Special issue]. Psychosomatic Medicine. 2008; 70:539-545. [PubMed: 18519880]

Leserman J, Ironson G, O'Cleirigh C, Fordiani J, Balbin E. Stressful life events and adherence in HIV. AIDS Patient Care and STDs. 2008; 22:403-411.10.1089/apc.2007.0175 [PubMed: 18373416]

Leserman J, Pence BW, Whetten K, Mugavero MJ, Thielman NM, Swartz MS, Stangl D. Relation of lifetime trauma and depressive symptoms to mortality in HIV. The American Journal of Psychiatry. 2007; 164:1707-1713.10.1176/appi.ajp.2007.06111775 [PubMed: 17974936]

Leserman J, Petitto JM, Gu H, Gaynes BN, Barroso J, Golden RN, Evans DL. Progression to AIDS, a clinical AIDS condition and mortality: Psychosocial and physiological predictors. Psychological Medicine. 2002; 32:1059-1073.10.1017/S0033291702005949 [PubMed: 12214787]

Leserman J, Whetten K, Lowe K, Stangl D, Swartz MS, Thiel-man NM. How trauma, recent stressful events, and PTSD affect functional health status and health utilization in HIV-infected patients in 
the South. Psychosomatic Medicine. 2005; 67:500-507.10.1097/01.psy.0000160459.78182.d9 [PubMed: 15911916]

Low CA, Stanton AL, Bower JE, Gyllenhammer L. A randomized controlled trial of emotionally expressive writing for women with metastatic breast cancer. Health Psychology. 2010; 29:460 466.10.1037/a0020153 [PubMed: 20658835]

Lumley MA, Leisen JC, Partridge R, Meyer TM, Radcliffe AM, Macklem DJ, Granda JL. Does emotional disclosure about stress improve health in rheumatoid arthritis? Randomized, controlled trials of written and spoken disclosure. Pain. 2011; 152:866-877.10.1016/j.pain.2011.01.003 [PubMed: 21315515]

Lumley, MA.; Tojek, TM.; Macklem, DJ. Effects of written emotional disclosure among repressive and alexithymic people. In: Lepore, SJ.; Smyth, JM., editors. The writing cure: How expressive writing promotes health and emotional well-being. Washington, DC: American Psychological Association; 2002. p. 75-95.

Mayne TJ, Vittinghoff E, Chesney MA, Barrett DC, Coates TJ. Depressive affect and survival among gay and bisexual men infected with HIV. Archives of Internal Medicine. 1996; 156:22332238.10.1001/archinte.1996.00440180095012 [PubMed: 8885823]

McNair, DM.; Lorr, M.; Droppleman, LF. Profile of Mood States. San Diego, CA: Educational and Industrial Testing Service; 1992.

Monson CM, Schnurr PP, Resick PA, Friedman MJ, Young-Xu Y, Stevens SP. Cognitive processing therapy for veterans with military-related posttraumatic stress disorder. Journal of Consulting and Clinical Psychology. 2006; 74:898-907.10.1037/0022-006X.74.5.898 [PubMed: 17032094]

Moskowitz JT, Hult JR, Bussolari C, Acree M. What works in coping with HIV? A meta-analysis with implications for coping with serious illness. Psychological Bulletin. 2009; 135:121-141.10.1037/ a0014210 [PubMed: 19210056]

O’Cleirigh C, Ironson G, Antoni M, Fletcher MA, McGuffey L, Balbin E, Solomon G. Emotional expression and depth processing of trauma and their relation to long-term survival in patients with HIV/AIDS. Journal of Psychosomatic Research. 2003; 54:225-235. [PubMed: 12614832]

O’Cleirigh C, Ironson G, Balbin E, George A, Antoni M, Schneiderman, Solomon G. Emotional processing of trauma predicts HIV disease progression at 1 year follow-up: Finding meaning as mediator of this relationship. Psychosomatic Medicine. 2002; 64(1):102. Abstract.

O'Cleirigh C, Ironson G, Fletcher MA, Schneiderman N. Written emotional disclosure and processing of trauma are associated with protected health status and immunity in people living with HIV/ AIDS. British Journal of Health Psychology. 2008; 13:81-84.10.1348/135910707X250884 [PubMed: 18230237]

O’Cleirigh C, Skeer M, Mayer KH, Safren SA. Functional impairment and health care utilization among HIV-infected men who have sex with men: The relationship with depression and posttraumatic stress. Journal of Behavioral Medicine. 2009; 32:466-477.10.1007/s10865-009-9217-4 [PubMed: 19526337]

Pence BW, Reif S, Whetten K, Leserman J, Stangl D, Swartz M, Mugavero MJ. Minorities, the poor, and survivors of abuse: HIV-infected patients in the U.S. deep South. Southern Medical Journal. 2007; 100:1114-1122.10.1097/01.smj.0000286756.54607.9f [PubMed: 17984744]

Pennebaker, JW. The psychology of physical symptoms. New York, NY: Springer-Verlag; 1982.

Pennebaker, JW. Opening up: The healing power of expressing emotions. New York, NY: Guilford Press; 1997. Rev. ed

Pennebaker JW, Barger SD, Tiebout J. Disclosure of traumas and health among holocaust survivors. Psychosomatic Medicine. 1989; 51:577-589. [PubMed: 2798704]

Pennebaker JW, Beall SK. Confronting a traumatic event: Toward an understanding of inhibition and disease. Journal of Abnormal Psychology. 1986; 95:274-281.10.1037/0021-843X.95.3.274 [PubMed: 3745650]

Pennebaker JW, Susman JR. Disclosure of traumas and psychosomatic processes [Special issue]. Social Science \& Medicine. 1988; 26:327-332. [PubMed: 3279521]

Petrie KJ, Fontanilla I, Thomas MG, Booth RJ, Pennebaker JW. Effect of written emotional expression on immune function in patients with human immunodeficiency virus infection: A randomized trial. 
Psychosomatic Medicine. 2004; 66:272-275.10.1097/01.psy.0000116782.49850.d3 [PubMed: 15039514]

Raudenbush, SW.; Bryk, AS.; Cheong, YF.; Congdon, R.; du Toit, M. HLM 6: Hierarchical linear and nonlinear modeling (Version 6.06) [Computer software]. Lincolnwood, IL: Scientific Software International; 2004.

Reisner SL, Mimiaga MJ, Safren SA, Mayera KH. Stressful or traumatic life events, post-traumatic stress disorder (PTSD) symptoms, and HIV sexual risk taking among men who have sex with men. AIDS Care. 2009; 21:1481-1489.10.1080/09540120902893258 [PubMed: 20024727]

Resick PA, Galovski TE, Uhlmansiek MO, Scher CD, Clum GA, Young-Xu Y. A randomized clinical trial to dismantle components of cognitive processing therapy for posttraumatic stress disorder in female victims of interpersonal violence. Journal of Consulting and Clinical Psychology. 2008; 76:243-258.10.1037/0022-006X.76.2.243 [PubMed: 18377121]

Resick PA, Nishith P, Weaver TL, Astin MC, Feuer CA. A comparison of cognitive-processing therapy with prolonged exposure and a waiting condition for the treatment of chronic posttraumatic stress disorder in female rape victims. Journal of Consulting and Clinical Psychology. 2002; 70:867-879.10.1037/0022-006X.70.4.867 [PubMed: 12182270]

Resick PA, Schnicke MK. Cognitive processing therapy for sexual assault victims. Journal of Consulting and Clinical Psychology. 1992; 60:748-756.10.1037/0022-006X.60.5.748 [PubMed: 1401390]

Resick, PA.; Schnicke, MK. Cognitive processing therapy for rape victims: A treatment manual. Newbury Park, CA: Sage; 1996.

Richards JM, Beal WE, Seagal JD, Pennebaker JW. Effects of disclosure of traumatic events on illness behavior among psychiatric prison inmates. Journal of Abnormal Psychology. 2000; 109:156160.10.1037/0021-843X.109.1.156 [PubMed: 10740948]

Rivkin ID, Gustafson J, Weingarten I, Chin D. The effects of expressive writing on adjustment to HIV. AIDS and Behavior. 2006; 10:13-26.10.1007/s10461-005-9051-9 [PubMed: 16421649]

Rosenberg HJ, Rosenberg SD, Ernstoff MS, Wolford GL, Amdur RJ, Elshamy MR, Pennebaker JW. Expressive disclosure and health outcomes in a prostate cancer population. International Journal of Psychiatry in Medicine. 2002; 32:37-53.10.2190/AGPF-VB1G-U82E-AE8C [PubMed: 12075915]

Schoutrop MJA, Lange A, Hanewald G, Davidovich U, Salomon H. Structured writing and processing major stressful events: A controlled trial. Psychotherapy and Psychosomatics. 2002; 71:151157.10.1159/000056282 [PubMed: 12021557]

Sloan DM, Marx BP. A closer examination of the structured written disclosure procedure. Journal of Consulting and Clinical Psychology. 2004; 72:165-175.10.1037/0022-006X.72.2.165 [PubMed: 15065952]

Sloan DM, Marx BP, Greenberg EM. A test of written emotional disclosure as an intervention for posttraumatic stress disorder. Behaviour Research and Therapy. 2011; 49:299-304.10.1016/j.brat. 2011.02.001 [PubMed: 21367400]

Smyth JM. Written emotional expression: Effect sizes, outcome types, and moderating variables. Journal of Consulting and Clinical Psychology. 1998; 66:174-184.10.1037/0022-006X.66.1.174 [PubMed: 9489272]

Smyth JM. Written disclosure: Evidence, potential mechanism, and potential treatment. Advances in Mind-Body Medicine. 1999a; 15:179-184. [PubMed: 10446473]

Smyth JM, Hockemeyer JR, Tulloch H. Expressive writing and post-traumatic stress disorder: Effects on trauma symptoms, mood states, and cortisol reactivity. British Journal Of Health Psychology. 2008; 13:85-93.10.1348/135910707X250866

Smyth JM, Stone AA, Hurewitz A, Kaell A. Effects of writing about stressful experiences on symptom reduction in patients with asthma or rheumatoid arthritis: A randomized trial. Journal of the American Medical Association. 1999b; 281:1304-1309.10.1001/jama.281.14.1304 [PubMed: 10208146]

Stanton AL, Danoff-Burg S, Sworowski LA, Collins CA, Branstetter AD, Rodriguez-Hanley A, Austenfeld JL. Randomized, controlled trial of written emotional expression and benefit finding in 
breast cancer patients. Journal of Clinical Oncology. 2002; 20:4160-4168.10.1200/JCO. 2002.08.521 [PubMed: 12377959]

Stanton AL, Kirk SB, Cameron CL, Danoff-Burg S. Coping through emotional approach: Scale construction and validation. Journal of Personality and Social Psychology. 2000; 78:11501169.10.1037/0022-3514.78.6.1150 [PubMed: 10870915]

Temoshok LR, Wald RL, Synowski S, Garzino-Demo A. Coping as a multisystem construct associated with pathways mediating HIV-relevant immune function and disease progression [Special issue]. Psychosomatic Medicine. 2008; 70:555-561.10.1097/PSY.0b013e318177354f [PubMed: 18519884]

van Middendorp H, Geenen R, Sorbi MJ, van Doornen LP, Bijlsma JJ. Health and physiological effects of an emotional disclosure intervention adapted for application at home: A randomized clinical trial in rheumatoid arthritis. Psychotherapy and Psychosomatics. 2009; 78:145151.10.1159/000206868 [PubMed: 19270469]

Wagner LJ, Hilker KA, Hepworth JT, Wallston KA. Cognitive adaptability as a moderator of expressive writing effects in an HIV sample. AIDS and Behavior. 2010; 14:410-420.10.1007/ s10461-008-9427-8 [PubMed: 18607714]

Warner LJ, Lumley MA, Casey RJ, Pierantoni W, Salazar R, Zoratti EM, Simon MR. Health effects of written emotional disclosure in adolescents with asthma: A randomized, controlled trial. Journal of Pediatric Psychology. 2006; 31:557-568.10.1093/jpepsy/jsj048 [PubMed: 16014820]

Whetten K, Leserman J, Lowe K, Stangl D, Thielman N, Swartz M, Moore M. Prevalence of childhood sexual abuse and physical trauma in an HIV-positive sample from the deep South. American Journal of Public Health. 2006; 96:1028-1030.10.2105/AJPH.2005.063263 [PubMed: 16670226]

Whetten K, Reif S, Whetten R, Murphy-McMillan LK. Trauma, mental health, distrust, and stigma among HIV positive persons: Implications for effective care [Special issue]. Psychosomatic Medicine. 2008; 70:531-538.10.1097/PSY.0b013e31817749dc [PubMed: 18541904]

Willmott L, Harris P, Gellaitry G, Cooper V, Horne R. The effects of expressive writing following first myocardial infarction: A randomized controlled trial. Health Psychology. 2011; 30:642650.10.1037/a0023519 [PubMed: 21875209]

Wyatt GE, Longshore D, Chin D, Carmona JV, Loeb TB, Myers HF, Rivkin I. The efficacy of an integrated risk reduction intervention for HIV-positive women with child sexual abuse histories. AIDS and Behavior. 2004; 8:453-462.10.1007/s10461-004-7329-y [PubMed: 15690118]

Zlotnick C, Davidson J, Shea MT, Pearlstein T. Validation of the Davidson Trauma Scale in a sample of survivors of childhood sexual abuse. Journal of Nervous and Mental Disease. 1996; 184:255256.10.1097/00005053-199604000-00010 [PubMed: 8604037] 


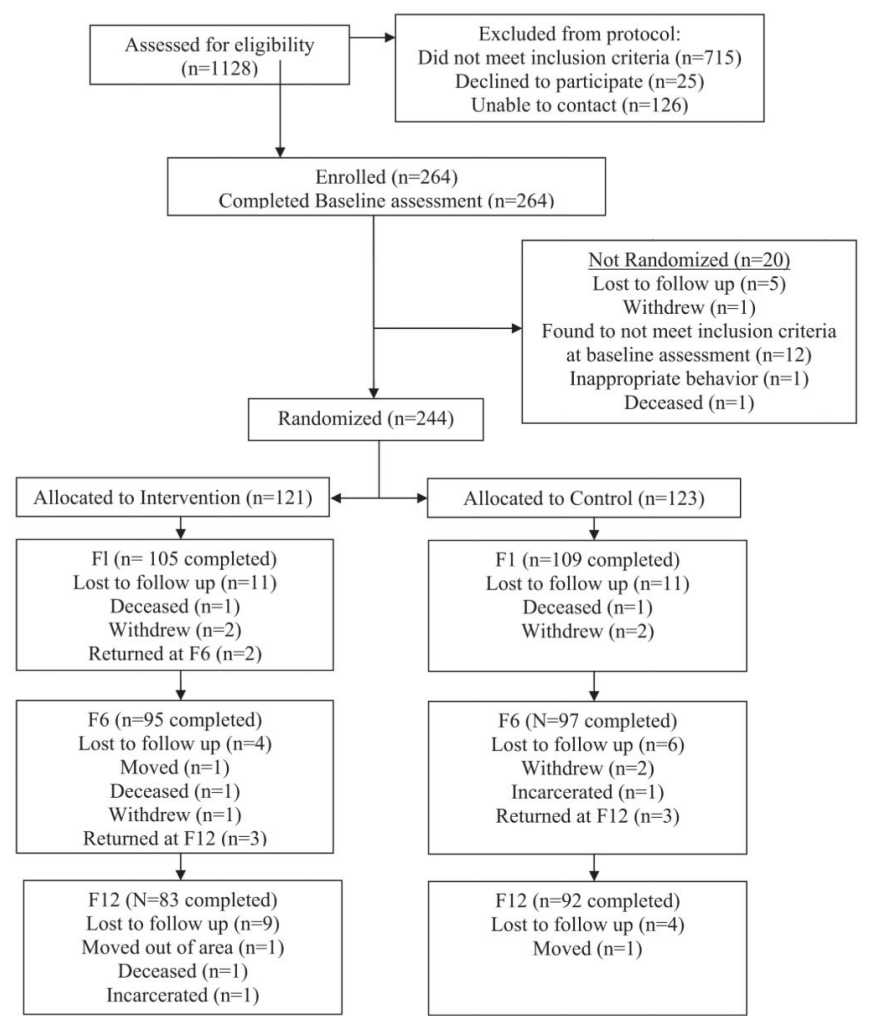

Figure 1.

Study CONSORT flow chart, February 2004-February 2010. F1, F6, and F12 stand for 1month follow-up, 6-month follow-up, and 12-month follow-up, respectively. 


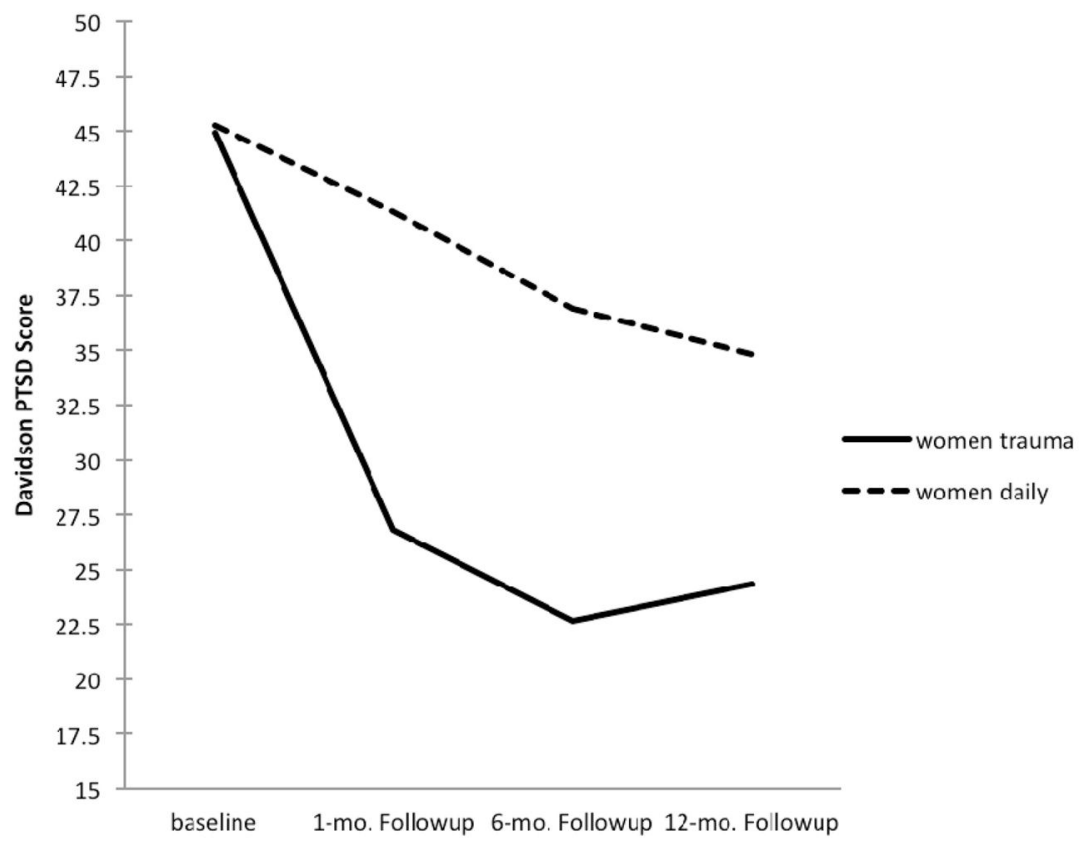

Figure 2.

Posttraumatic stress disorder (PTSD) symptoms for trauma-writing versus daily-writing groups for women with elevated PTSD symptoms (above the median) on the Davidson PTSD Scale (PTSDTOT >20). 


\section{Table 1}

Means and Standard Deviations (in Parentheses) for Main Study Outcomes Across Baseline and 1-, 6-, and 12-Month Follow-Ups

\begin{tabular}{|c|c|c|c|c|}
\hline Outcome & Baseline & 1 month & 6 month & 12 month \\
\hline \multicolumn{5}{|l|}{ PTSDTOT } \\
\hline Treatment & $27.69(23.84)$ & $20.63(23.72)$ & $17.66(20.13)$ & $18.08(20.41)$ \\
\hline Control & $28.65(23.46)$ & $23.84(21.93)$ & $19.83(21.73)$ & $17.89(22.42)$ \\
\hline \multicolumn{5}{|l|}{ HAM-D } \\
\hline Treatment & $9.61(6.36)$ & $8.41(6.26)$ & $8.13(6.46)$ & $7.54(6.24)$ \\
\hline Control & $10.32(6.82)$ & $8.99(7.27)$ & $8.30(6.60)$ & $7.09(5.56)$ \\
\hline \multicolumn{5}{|c|}{ HIV symptoms } \\
\hline Treatment & $0.25(0.43)$ & $0.24(0.43)$ & $0.19(0.40)$ & $0.22(0.42)$ \\
\hline Control & $0.21(0.41)$ & $0.25(0.44)$ & $0.27(0.45)$ & $0.26(0.44)$ \\
\hline \multicolumn{5}{|l|}{ CD4 } \\
\hline Treatment & $410(206)$ & $421(269)$ & $419(245)$ & $429(251)$ \\
\hline Control & 467 (259) & 466 (249) & $464(223)$ & $491(302)$ \\
\hline \multicolumn{5}{|l|}{ Viral load } \\
\hline Treatment & $47,666(126,768)$ & $38,100(100,172)$ & $47,406(114,877)$ & $56,577(142,846)$ \\
\hline Control & $18,480(57,401)$ & $24,166(79,005)$ & $28,743(94,105)$ & $24,056(68,682)$ \\
\hline \multicolumn{5}{|l|}{ Sample size ${ }^{a}$} \\
\hline Treatment & $120^{b}$ & $104^{d}$ & $94^{f}$ & $82^{h}$ \\
\hline Control & $122^{c}$ & $108^{e}$ & $96^{g}$ & $91^{i}$ \\
\hline
\end{tabular}

Note . PTSDTOT = Davidson PTSD (Posttraumatic Stress Disorder) Scale; HAM-D = Hamilton Depression Scale; HIV symptoms = HIV symptom checklist.

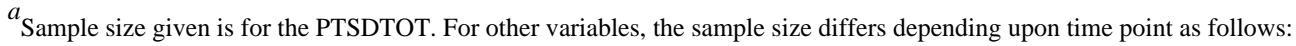

${ }^{b}$ HAM-D $(N=115)$, HIV symptoms $(N=121)$, CD4 $(N=118)$, and viral load $(N=118)$;

${ }^{c}$ HIV symptoms $(N=123)$, CD4 $(N=121)$, and viral load $(N=121)$;

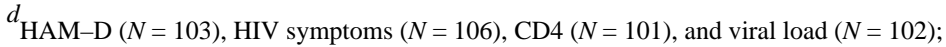

$e_{\mathrm{CD} 4}(N=107)$ and viral load $(N=105) ;$

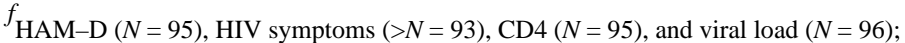

${ }^{g} \mathrm{CD} 4(N=92)$ and viral load $(N=89)$;

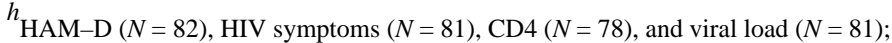

${ }^{i}$ HAM-D $(N=89)$, HIV symptoms $(N=88)$, CD4 $(N=87)$, and viral load $(N=87)$. 


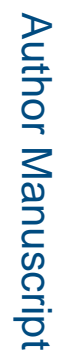

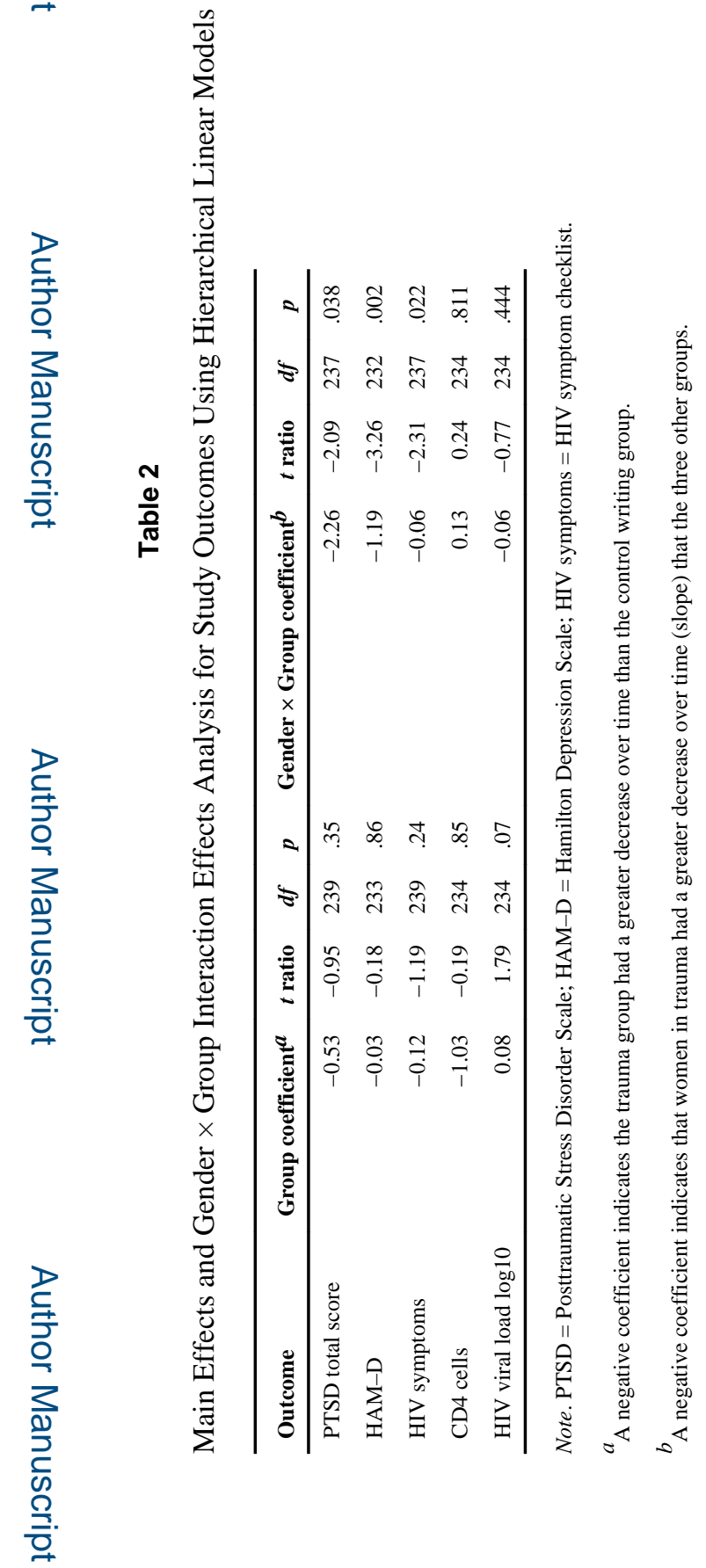



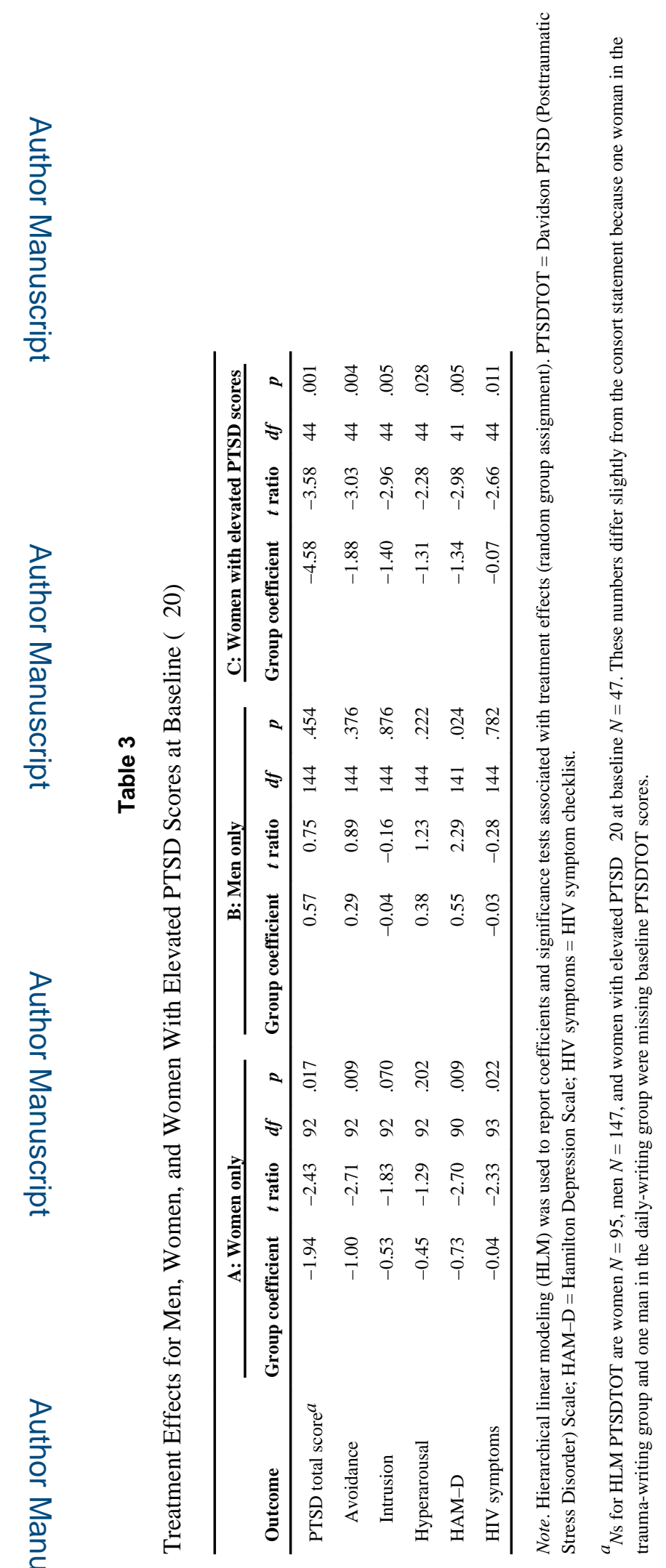

J Consult Clin Psychol. Author manuscript; available in PMC 2015 June 13. 
Table 4

Means and Standard Deviations (in Parentheses) for Main Study Outcomes (With A Significant Group by Gender Interaction) for Women and Men Separately Across Baseline and at 1-, 6-, and 12-Month Follow-Ups

\begin{tabular}{|c|c|c|c|c|}
\hline Outcome & Baseline & 1 month & 6 month & 12 month \\
\hline \multicolumn{5}{|l|}{ Women } \\
\hline \multicolumn{5}{|l|}{ PTSDTOT } \\
\hline Treatment & $25.31(25.93)$ & $17.67(19.75)$ & $15.77(20.23)$ & $16.57(17.33)$ \\
\hline Control & $26.98(22.98)$ & $25.65(23.22)$ & $20.83(23.30)$ & $22.32(26.35)$ \\
\hline \multicolumn{5}{|l|}{ HAM-D } \\
\hline Treatment & $9.56(7.63)$ & $6.88(5.11)$ & $6.56(5.40)$ & $7.08(5.83)$ \\
\hline Control & $9.92(6.14)$ & $9.00(7.22)$ & $9.61(6.68)$ & $8.05(5.82)$ \\
\hline \multicolumn{5}{|c|}{ HIV symptoms } \\
\hline Treatment & $0.27(0.45)$ & $0.27(0.45)$ & $0.13(0.34)$ & $0.21(0.41)$ \\
\hline Control & $0.31(0.47)$ & $0.30(0.47)$ & $0.39(0.49)$ & $0.39(0.50)$ \\
\hline \multicolumn{5}{|l|}{ Sample size ${ }^{a}$} \\
\hline Treatment & $48^{b}$ & $43^{d}$ & $41^{e}$ & 38 \\
\hline Control & $47^{c}$ & 46 & 41 & $40^{f}$ \\
\hline \multicolumn{5}{|l|}{ Men } \\
\hline \multicolumn{5}{|l|}{ PTSDTOT } \\
\hline Treatment & $29.28(22.38)$ & $22.72(26.12)$ & $19.13(20.12)$ & $19.39(22.86)$ \\
\hline Control & $29.69(23.86)$ & $22.50(20.93)$ & $19.09(20.67)$ & $14.41(18.31)$ \\
\hline \multicolumn{5}{|l|}{ HAM-D } \\
\hline Treatment & $9.64(5.44)$ & $9.50(6.81)$ & $9.31(6.97)$ & $7.93(6.62)$ \\
\hline Control & $10.58(7.25)$ & $8.98(7.36)$ & $7.33(6.43)$ & $6.34(5.29)$ \\
\hline \multicolumn{5}{|c|}{ HIV symptoms } \\
\hline Treatment & $0.23(0.43)$ & $0.21(0.41)$ & $0.25(0.43)$ & $.23(.43)$ \\
\hline Control & $0.15(0.36)$ & $0.21(0.41)$ & $0.18(0.39)$ & $.16(.37)$ \\
\hline \multicolumn{5}{|l|}{ Sample size ${ }^{a}$} \\
\hline Treatment & $72^{g}$ & $61^{i}$ & $53^{j}$ & $44^{k}$ \\
\hline Control & $75^{h}$ & 62 & 55 & $51^{l}$ \\
\hline
\end{tabular}

Note . PTSDTOT = Davidson PTSD (Posttraumatic Stress Disorder) Scale; HAM-D = Hamilton Depression Scale; HIV symptoms = HIV symptom checklist.

${ }^{a}$ Sample size is for PTSDTOT. For other variables, the sample size is as follows:

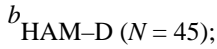

${ }^{c}$ HAM-D $(N=48)$ and HIV symptoms $(N=48)$;

$d_{\text {HIV symptoms }(N=44) \text {; }}$

$e^{e}$ HIV symptoms $(N=40)$;

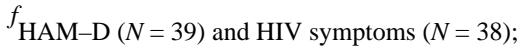

${ }^{g} \mathrm{HAM}-\mathrm{D}(N=70)$; 


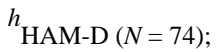

${ }^{i} \operatorname{HAM}-\mathrm{D}(N=60)$;

${ }^{j}$ HAM-D $(N=54)$;

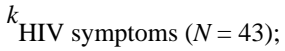

${ }^{l}$ HAM-D and HIV symptoms $(N=50)$. 
Table 5

Means and Standard Deviations (in Parentheses) for Main Study Outcomes for Women With Elevated PTSD Scores at Baseline ( 20 ) Across Baseline and 1-, 6-, and 12-Month Follow-Ups

\begin{tabular}{|c|c|c|c|c|}
\hline Outcome & Baseline & 1 month & 6 month & 12 month \\
\hline \multicolumn{5}{|l|}{ PTSDTOT } \\
\hline Treatment & $44.91(23.13)$ & $26.75(21.20)$ & $22.60(23.49)$ & $24.28(19.89)$ \\
\hline Control & $45.25(19.07)$ & $41.30(22.94)$ & $36.86(24.94)$ & $34.79(30.60)$ \\
\hline \multicolumn{5}{|l|}{ HAM-D } \\
\hline Treatment & $14.86(7.51)$ & 7.85 (4.36) & $6.52(5.60)$ & $9.72(6.07)$ \\
\hline Control & $13.42(5.56)$ & $12.35(7.27)$ & $11.71(5.97)$ & $10.42(6.07)$ \\
\hline \multicolumn{5}{|c|}{ HIV symptoms } \\
\hline Treatment & $0.33(0.48)$ & $0.29(0.46)$ & $0.15(0.37)$ & $0.28(0.46)$ \\
\hline Control & $0.33(0.48)$ & $0.35(0.49)$ & $0.57(0.51)$ & $0.42(0.51)$ \\
\hline \multicolumn{5}{|l|}{ Sample size ${ }^{a}$} \\
\hline Treatment & $24^{b}$ & $20^{c}$ & $21^{d}$ & 18 \\
\hline Control & 24 & 23 & 21 & $20^{e}$ \\
\hline
\end{tabular}

Note . PTSDTOT = Davidson PTSD (Posttraumatic Stress Disorder) Scale; HAM-D = Hamilton Depression Scale; HIV symptoms = HIV symptom checklist.

${ }^{a}$ Sample size given is for PTSDTOT. Where the sample size differs for other variables, the sample size is as follows:

$b_{\text {HAM-D }}(N=21)$;

${ }^{c}$ HIV symptoms $(N=21)$;

${ }^{d}$ HIV symptoms $(N=20)$;

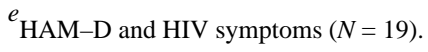


Table 6

Effect Sizes and 95\% Confidence Intervals (in Brackets) for Symptoms of PTSD and Depression

\begin{tabular}{|c|c|c|c|c|}
\hline \multirow[b]{2}{*}{ Variable } & \multicolumn{2}{|c|}{ PTSD } & \multicolumn{2}{|c|}{ Depression } \\
\hline & 6 months & 12 months & 6 months & 12 months \\
\hline \multicolumn{5}{|l|}{ All women } \\
\hline Pre-post change trauma group & $0.49[0.18,0.81]$ & $0.45[0.12,0.78]$ & $0.36[0.04,0.68]$ & $0.37[0.03,0.70]$ \\
\hline Pre-post trauma vs. pre-post control & $0.21[-0.23,0.65]$ & $0.22[-0.24,0.67]$ & $0.44[0.00,0.89]$ & $0.25[-0.20,0.71]$ \\
\hline \multicolumn{5}{|l|}{ Women with baseline PTSD score $\geq 20$} \\
\hline Pre-post change trauma group & $1.12[0.67,1.57]$ & $1.15[0.66,1.64]$ & $0.89[0.42,1.37]$ & $0.68[0.16,1.20]$ \\
\hline Pre-post trauma vs. pre-post control & $0.63[0.01,1.26]$ & $0.45[-0.21,1.11]$ & $0.91[0.26,1.55]$ & $0.47[-0.22,1.16]$ \\
\hline \multicolumn{5}{|l|}{ All men } \\
\hline Pre-post change trauma group & $0.38[0.10,0.65]$ & $0.42[0.11,0.72]$ & $0.06[-0.21,0.34]$ & $0.17[-0.14,0.48]$ \\
\hline Pre-post trauma vs. pre-post control & $-0.09[-0.42,0.30]$ & $-0.27[-0.68,0.14]$ & $-0.52[-0.90,0.13]$ & $-0.37[-0.79,0.05]$ \\
\hline \multicolumn{5}{|l|}{ Entire sample } \\
\hline Pre-post change trauma group & $0.43[0.23, .0 .64]$ & $0.44[0.22,0.66]$ & $0.16[-0.05,0.37]$ & $0.27[0.05,0.49]$ \\
\hline Pre-post trauma vs. pre-post control & $0.04[-0.25, .0 .33]$ & $-0.06[-0.36,0.25]$ & $-0.05[-0.33,0.24]$ & $-0.09[-0.39,0.22]$ \\
\hline
\end{tabular}

Note. PTSD = Posttraumatic Stress Disorder. 